\title{
Status and habitat requirements of Physaria thamnophila, an endangered species of Tamaulipan thornscrub
}

\section{Norma Fowler ${ }^{\mathrm{a}}$, Dana Price ${ }^{\mathrm{b}}$, Chris Best ${ }^{\mathrm{c}}$, and Alice Hempel ${ }^{\mathrm{d}}$}

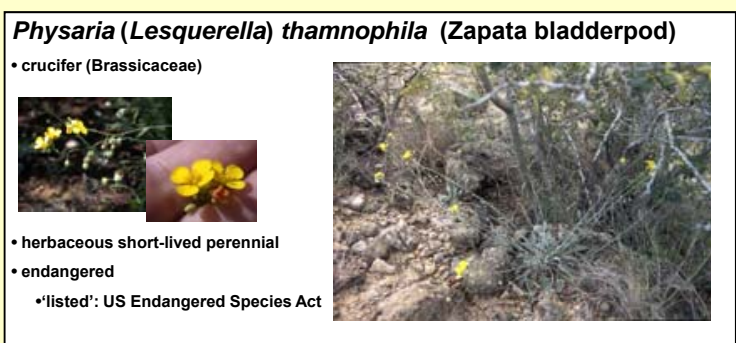

Plant community, study sites

- part of Tamaulipan thornscrub biome

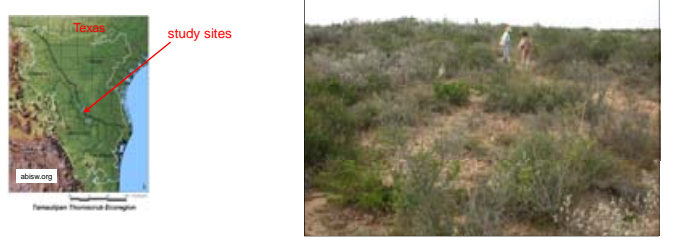

-known populations are on terraces above Rio Grande

- all four study sites had highly erodible calcareous soils

-study sites were dominated by the shrubs Acacia rigidula (blackbrush)

and Leucophyllum frutescens (cenizo)

- the non-native invasive grasses common in similar sites (Pennisetum ciliare, buffelgrass;

Dichanthium annulatum, Kleberg bluestem) were absent or sparse in the study sites

- the study sites had a rich flora of native shrubs, grasses, forbs, and cacti; our data

correct and ex

- threats to $P$. thamnophila and to Tamaulipan thornscrub in Texas include conversion of

habitat to agriculture or pasture; road construction; urbanization; oil and gas

extraction; border fence construction; non-native grasses

\section{Methods}

- 4 populations: Arroyo Morteros (AM), Arroyo Ramirez (AR), Cuellar (CL), Santa Margarita (SM) part of Cuellar roller-chopped (right-of-way maintenance) in December 2000;

high density of $P$. thamnophila in cleared area in February 2001
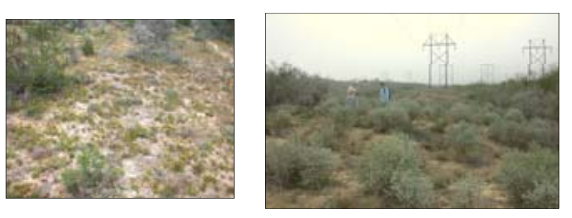

pictures of
Cuellar cleared a University of Texas, Austin, TX nfowler@uts.cc.utexas.edu

b Texas Parks and Wildlife Department (present affiliation:

Environmental Resources, US ACE, Albuquerque, NM)

' Lower Rio Grande National Wildlife Refuge, USFWS

(present affiliation: Ecological Services, USFWS, Austin, TX)

d Texas A\&M University, Kingsville, TX

\section{Methods, continued}

- permanent transects through each of the four populations

- permanent plots at random points along transects

thamnophila censuses

- censuses of $P$. thamnophila in Mar, April, or May 2003-200

- in each year, $1-4$ of the $P$. thamnophila populations censused

if a census was made

-all plants in each plot were counted, plus

-in some years, \# reproductive plants in each plot were counted

- in some years, \# seedlings in each plot were counted

vegetation data

- collected in AM 2007; AR 2003; CL 2002 and 2007; SM 2004

5 sub-plots/census plot

-recorded each plant species present in each sub-plot, in each of 4 height categories: $0-0.5$
$\mathrm{~m}, 0.5-1 \mathrm{~m}, 1-2 \mathrm{~m}$, and $2-3 \mathrm{~m}$ above ground. There were no plants $>3 \mathrm{~m}$ tall.

- calculation of canopy cover index for each plot: (1) used upper $3 \mathrm{ht}$ categories only; (2)
summed $\#$ of ht categories with any plant in them in each subplot; (3) summed these values summed \# of ht cate
over the 5 subplots
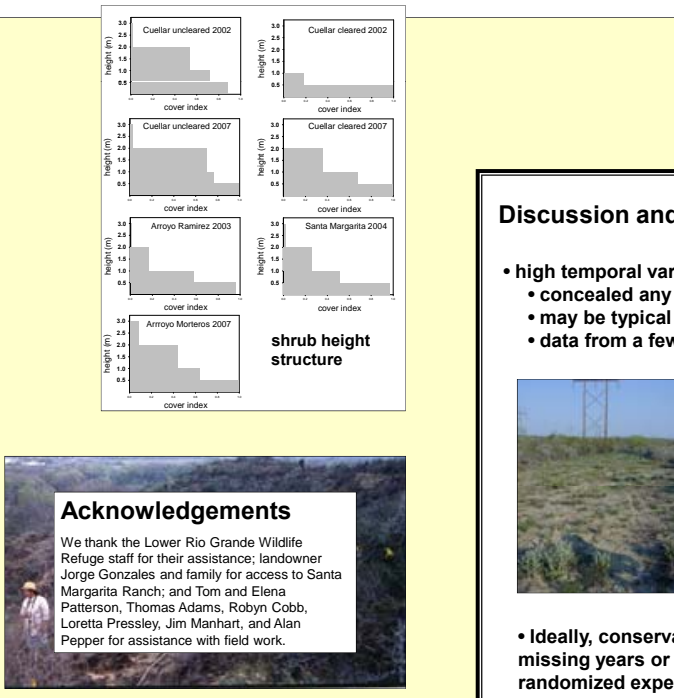

Results

- In both 2002 and 2007 , the CL cleared plots had lower canopy cover index values, greater
herbaceous-layer species richness, and more grass than the CL uncleared plots. [ANOVAs]

- Average density of $P$. thamnophila was greater in cleared than in uncleared $C L$ plots, if unoccupied
plots are included. In all five annual censuses of $C L$, a higher proportion of cleared plots had $P$.

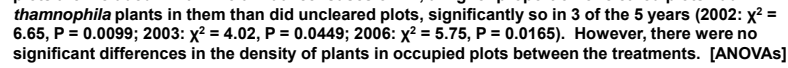

-Although the 3 unmanipulated sites (AM, AR,
and SM) differed significantly in canopy cover, and $S M$ ) differed significantly in canopy cover,
herbaceous-layer species richness, and grass density [ANOVAs], vegetation characteris
were not related to $P$. thamnophila plot occupancy in these sites llogis
with site as a class variable

- Canopy cover was significantly and
positively related to total $P$. thamnophile positively related to total P. , thamnophila
density 2004 and 2006 -2007 and to $P$.
thamnophila seedling density in 2007 . Herbaceous layer species-richness and gras
density were not related to $P$. thamnophila density were not selaces
density. [ANCOVAs]
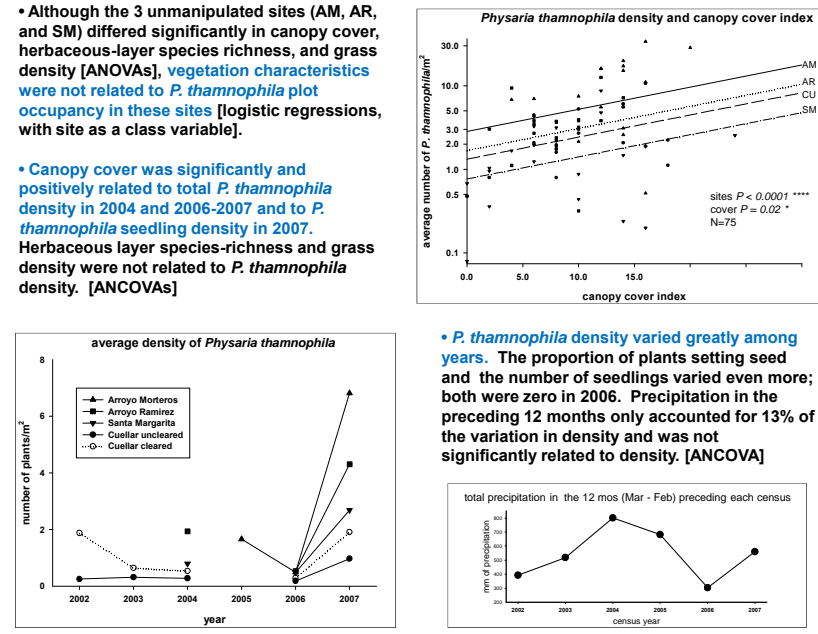
and the number of seedlings varied even more both were zero in 2006 . Precipitation in the
preceding 12 months only accounted for $13 \%$ of preceding 12 months only accounted for
the variation in density and was not
significantly related to density. [ANCOVA]

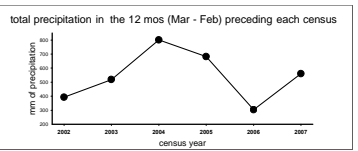

Discussion and Conclusions

- high temporal variation in population size

- may be typical of small herbaceous perennials in arid climates

- data from a few years insufficient to assess population status and management efforts

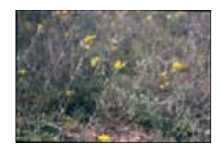

complex relationship between $P$. thamnophila and shrub cover

- more cleared plots than uncleared plots occupied by $P$. thamnophit $P$, thamnophila seedlings

areas, more litter under shrubs

mechanical clearing spread litter, perhap
seedlings away from surviving shrubs

most likely benefit of litter: reduction of soil erosion rates

- Ideally, conservation of endangered species would be based upon demographic data without randomized experiments, but such data are not available for most endangered plant species. demonstrate here how much can be learned from less-than-ideal data that were collected opportunistically as time and resources allowed. 